\title{
Detection of circulating antigens in serum samples of mice experimentally infected with Trichinella spiralis by a sandwich ELISA based on IgY
}

\author{
F. J. JING ${ }^{1,2}$, J. CUI ${ }^{1 *}$, R.D. LIU ${ }^{1}$, L. N. LIU ${ }^{1}$, P. JIANG ${ }^{1}$, Z. Q. WANG ${ }^{1 *}$ \\ ${ }^{1}$ Department of Parasitology, Medical College, Zhengzhou University, China, \\ *E-mail: cuij@zzu.edu.cn,wangzq@zzu.edu.cn; ${ }^{2}$ Department of Laboratorial Medicine, Wuhu Hospital \\ of Traditional Chinese Medicine, Anhui Province, China
}

\begin{abstract}
Summary
In the present study, a sandwich ELISA based on IgY (egg yolk immunoglobulin) was developed for detection of circulating antigens $(\mathrm{CAg})$ in sere of mice experimentally infected with Trichinella spiralis. The IgY-sandwich ELISA assay involved the use of chicken antibody IgY against excretory-secretory (ES) antigens of Trichinella spiralis muscle larvae as a capture antibody and mouse polyclonal antibody IgG to ES antigens as a detecting antibody. This method was able to detect as little as 3 $\mathrm{ng} / \mathrm{ml}$ of ES antigens added to normal mouse serum. A group of sixteen mice was orally inoculated with $500 \mathrm{~T}$. spiralis muscle larvae per animal. The serum samples from the infected mice were taken during $1-35$ days post-infection (dpi). The CAg was detectable as early as $8 \mathrm{dpi}$ in the sera of infected mice. The level of CAg increased dramatically during $13-15 \mathrm{dpi}$ and reached a peak at $22 \mathrm{dpi}$ and remained a plateau for 3 days, then declined gradually. Another peak of CAg occurred at $31 \mathrm{dpi}$. The anti-Trichinella antibodies was first detected in $14.3 \%$ of the infected mice at 2 weeks post-infection (wpi), and reached a peak positive rate of $100 \%$ at 5 wpi. Moreover, the infected mice were treated with abendazole at 5 wpi and the serum CAg levels increased significantly during $2-6$ days posttreatment (dpt) and then declined rapidly during $8-14 \mathrm{dpt}$. By $42 \mathrm{dpt}$, the CAg levels decreased to the undetected level, but the detection rate of antibodies was still $100 \%$. The IgY- sandwich ELISA appears to be a sensitive for detection of antigenemia of $T$. spiralis and valuable to judge the efficacy of chemotherapy in trichinellosis.
\end{abstract}

Keywords: Trichinella spiralis; circulating antigens; sandwich ELISA; IgY; abendazole

\section{Introduction}

Trichinellosis is a parasitic zoonosis caused by the tissuedwelling nematode Trichinella. Humans acquire the dise- ase by ingesting raw or insufficiently cooked meat of pigs or other animals containing the Trichinella larvae (Dvorožňáková et al., 2010, 2013). The adult worms live in the intestinal mucosa of flesh-eating animals and humans, while the larvae live in skeletal muscles of the same hosts (Kołodziej-Sobocińska et al., 2012). The clinical manifesttations of trichinellosis can be divided into two phases: an enteral phase and a muscular (parenteral or acute) phase, which can coexist for a period lasting from a few days to weeks. The hallmark of the intestinal phase is a non-specific gastroenteritis. Diarrhea, abdominal pain, nausea, and vomiting can occur. The muscular phase is associated with an inflammatory and allergic response to muscle invasion by the migrating larvae. Fever, eyelid or facial edema, myalgia, and eosinophilia are the main clinical manifestations (Pozio et al., 2003; Dvorožňáková et al., 2012).

Trichinella infection in animals and humans is widely distributed in the world. Of all of the countries of the world, Trichinella spp. infection has been documented in domestic animals (mainly pigs) and wildlife in $43(21.9 \%)$ and $66(33.3 \%)$ countries, respectively. Human trichinellosis has been documented in $55(27.8 \%)$ countries around the world (Pozio, 2007). In China, the overall seroprevalence of Trichinella infection in humans was $3.19 \%$. From 2004 to 2009, 15 outbreaks of human trichinellosis, consisting of 1,387 cases and four deaths, were reported in southwestern China (Cui et al., 2011). So, trichinellosis is a major food-borne zoonosis with health, social, and economic impacts in China (Cui et al., 2013).

The diagnosis of trichinellosis is rather difficult because fever, myalgia and eosinophilia are nonspecific, and this disease may be misdiagnosed. At present, muscle biopsy and serologic testing are used for diagnosing human trichinellosis (Yera et al., 2003; Gómez-Morales et al., 2008), but the biopsy technique is not sensitive to infections with small numbers of $T$. spiralis, and serologic tests (e.g., enzyme-linked immunosorbent assay (ELISA) using muscle 
larval excretory-secretory (ES) antigen or the synthetic antigen 3,6-dideoxy-D-arabinohexose [tyvelose]) for detecting IgG specific for Trichinella are not positive in pig and mice infected experimentally until 3 to 4 weeks after infection (Kapel \& Gamble, 2000; Gamble et al., 2004; Oltean et al., 2012; Wang et al., 2012;). Several studies have shown that the maximum positivity of $100 \%$ of ELISA in detecting anti-Trichinella antibodies was not reached until at least 1 to 3 months after human infection with the parasite (Bruschi et al., 1990; Morakote et al., 1991; Wang et al., 1998). In addition, the diagnostic methods based on detecting antibodies cannot provide a definite diagnosis of acute trichinellosis because the antibody detection is impossible to distinguish acute or past infection (Wang et al., 1998).

The detection of Trichinella circulating antigen (CAg) seems an effective way to discriminate between previous exposure and current infection. In this respect, the detection of Trichinella CAg takes a prominent place. Various methods have been developed for detecting Trichinella $\mathrm{CAg}$, including counterimmunoelectrophoresis (Smith \& Kennedy, 1984), latex agglutination test (Choy et al., 1988), immunoradiometric assay (Ivanoska et al., 1989), Direct enzyme-linked immunosorbent assay (ELISA) (DeLa-Rosa et al., 2001) and sandwich ELISA (Arriaga et al., 1995; Hegazy et al., 1996; Rodriguez-Osorio et al., 1999; $\mathrm{Li}$ and Ko, 2001). However, because the serum levels of circulating antigens of $T$. spiralis are quite low, the detection rate of CAg in serum samples was usually only $30 \%-$ $50 \%$ in the patients with clinical trichinellosis (Nishiyama et al., 1992). Hence, the serological methods available for detecting CAg cannot be used to serodiagnosis of trichinellosis (Dupouy-Camet et al., 2002; Gamble et al., 2004). Chicken IgY has been recognized as an excellent source of polyclonal antibodies for over decades (Tini et al., 2002). Specific antibodies produced in chickens offer several important advantages over producing antibodies in mammals, for example, avoiding the interference in immunological assays caused by the rheumatoid factors (Larsson \& Sjouist, 1988), complement system (Larsson et al., 1992), or anti-mammalian antibodies (Juliarena et al., 2007). Furthermore, chicken IgY recognize more epitopes than the corresponding mammalian antibodies (Svendsen \& Hau, 2006). Because of the above advantages, IgY has been widely used to diagnosis of different diseases (Sunwoo et al., 2006; Dias da Silva \& Tambourgi, 2010).

In the present study, we developed a sandwich ELISA based on IgY (IgY- sandwich ELISA) for detection of CAg in serum samples of mice experimentally infected with Trichinella spiralis. The assay consisted of chicken IgY against the excretory-secretory (ES) antigens of $T$. spiralis muscle larvae as a capture antibody and mouse anti-ES antigen polyclonal antibodies as a detecting antibody. Moreover, the serum levels of CAg of the infected mice after treatment with albendazole was also investigated. In comparison, antibodies were assayed by indirect ELISA using ES antigens of $T$. spiralis muscle larvae.

\section{Materials and methods}

\section{Parasite}

The isolate (ISS534) of T. spiralis used in the study were obtained from domestic pigs in Nanyang city of Henan Province, China. This isolate was maintained by serial passage in Kunming mice at 6-8-month intervals. Muscle larvae were recovered by acid pepsin digestion as described previously (Li et al., 2010).

\section{Mice and serum samples}

BALB/c mice aged 6 weeks were provided by the Experimental Animal Center of Henan province. Sixteen mice weighing 20 to $25 \mathrm{~g}$ were orally infected with 500 larvae per animal of $T$. spiralis larvae. Blood was collected daily until 35 days post infection (dpi). Moreover, to evaluate the effect of chemotherapy on antigen levels, the infected mice were divided into two subgroups: albendazole treated group (11 mice) and its corresponding untreated group (5 mice). Albendazole (Hanjiang Pharmaceutical Factory of Shanxi, China) suspended in distilled water was administered intragastrically at $35 \mathrm{dpi}$ in a dose of $370 \mathrm{mg} / \mathrm{kg}$ body weight, twice daily, for 7 consecutive days (DupouyCamet et al., 2002). The untreated group was given only distilled water. Blood was collected at 2 days-interval after treatment. The sera of mice before infection were also collected. All sera were stored at $-20{ }^{\circ} \mathrm{C}$ until use. At the end of the study, all the infected mice were euthanized, skinned, and eviscerated. The carcasses of each mouse were individually digested by artificial digestion method as described previously (Li et al., 2010). The larvae were collected and counted from each mouse. Results were expressed as reduction rates, calculated as the percent of recovered larvae versus those recovered from control mice.

Preparation and characterization of chicken anti-ES $\operatorname{Ig} Y$

The ES antigens of $T$. spiralis muscle larvae were prepared as described previously (Wang et al., 2011). The preparation and characterization of chicken IgY against ES antigens were developed according to the method established in our laboratory (Li et al., 2010). In brief, 24-week-old Roman hens that were maintained in a standard SPF condition were subcutaneously immunized with ES antigens for four times. Each hen was immunized with $500 \mu \mathrm{g}$ of ES antigens firstly and then boosted with $250 \mu \mathrm{g}$ of ES antigens for three times at 10-day intervals. Eggs were collected daily before immunization and after the last immunization. IgY was extracted from yolk according to the water dilution method (Akita \& Nakai, 1993). The protein content of IgY was determined by the method described by Bradford (1976). The purified IgY was analyzed by SDS-PAGE.

\section{Preparation of poloclonal $\operatorname{Ig} G$ antibodies}

Poloclonal IgG antibodies against ES antigens of T. spiralis muscle larvae were produced in female BALB/c mice (6 weeks old), according to the methods as described previously (Liu et al., 2013). Normal mouse serum served as the negative control. 


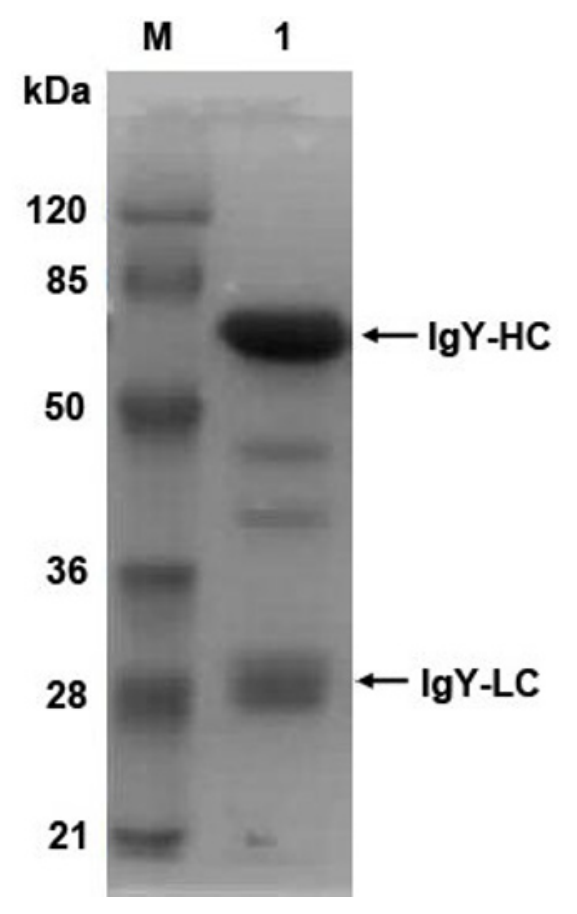

Fig. 1. Analysis of IgY by $12 \%$ SDS-PAGE in reducing condition. $15 \mu \mathrm{g}$ of protein was loaded for each lane. $M$ : Protein marker with low molecular weights; 1 Purified IgY from immunized egg yolk. IgY-HC = IgY heavy chain; IgY-LC = IgY light chain

IgY-sandwich ELISA for detection of circulating antigen An IgY-sandwich ELISA was developed using IgY to capture free antigens present in serum samples, and polyclonal IgG to selectively react with ES components of muscle larvae. In brief, 96-wells ELISA plates (Corning,
USA) were coated with $7.5 \mu \mathrm{g}$ IgY proteins/well in $100 \mu \mathrm{l}$ of bicarbonate buffer ( $\mathrm{pH} 9.6)$ and incubated overnight at $4^{\circ} \mathrm{C}$. Plates were washed three times with $0.05 \%$ Tween20 in PBS (PBST). After blocking with $5 \%$ skimmed milk in PBST, serum samples were diluted at 1:100 and $\mathrm{IgG}$ was used at 1:200 dilutions. For the detection of bound IgG, HRP-conjugated sheep anti-mouse IgG (Sigma, USA) was used at 1:5,000 dilutions. The reactions were detected by addition of the substrate O-phenylendiamine dihydrochloride (Sigma, USA) plus $\mathrm{H}_{2} \mathrm{O}_{2}$ and stopped with $50 \mu \mathrm{l} /$ well of $2 \mathrm{M} \mathrm{H}_{2} \mathrm{SO}_{4}$. Optical density (OD) values at $490 \mathrm{~nm}$ were measured with a microplate reader (TECAN, Austria). All samples were run in duplicate. Murine sera before infection and PBS were used as negative control and blank control, respectively. All the values were recorded after appropriate blank correction. The reactivity of CAg was expressed as the lower detection limit (LDL) in nanograms of ES antigens $/ \mathrm{ml}$. The ES antigen standard was serially diluted in normal serum, ranging from $1 \mathrm{ng}$ to $5 \mathrm{mg} / \mathrm{ml}$ and BSA was used as negative control.

\section{Indirect ELISA for detection of antibodies}

Anti-Trichinella antibodies in the infected mice before infection, $1-5$ weeks post-infection (wpi) and $1-6$ weeks post-treatment (wpt) were weekly assayed by indirect ELISA with ES antigens. It was performed as previously described (Wang et al. 2006).

In both ELISAs, Test sera/negative sera OD values $<2.1$ were regarded as negative and those $\geq 2.1$ as positive. The cut-off values of IgY-sandwich ELISA for detecting CAg and indirect ELISA for detecting antibodies were 0.21 and 0.20 , respectively.

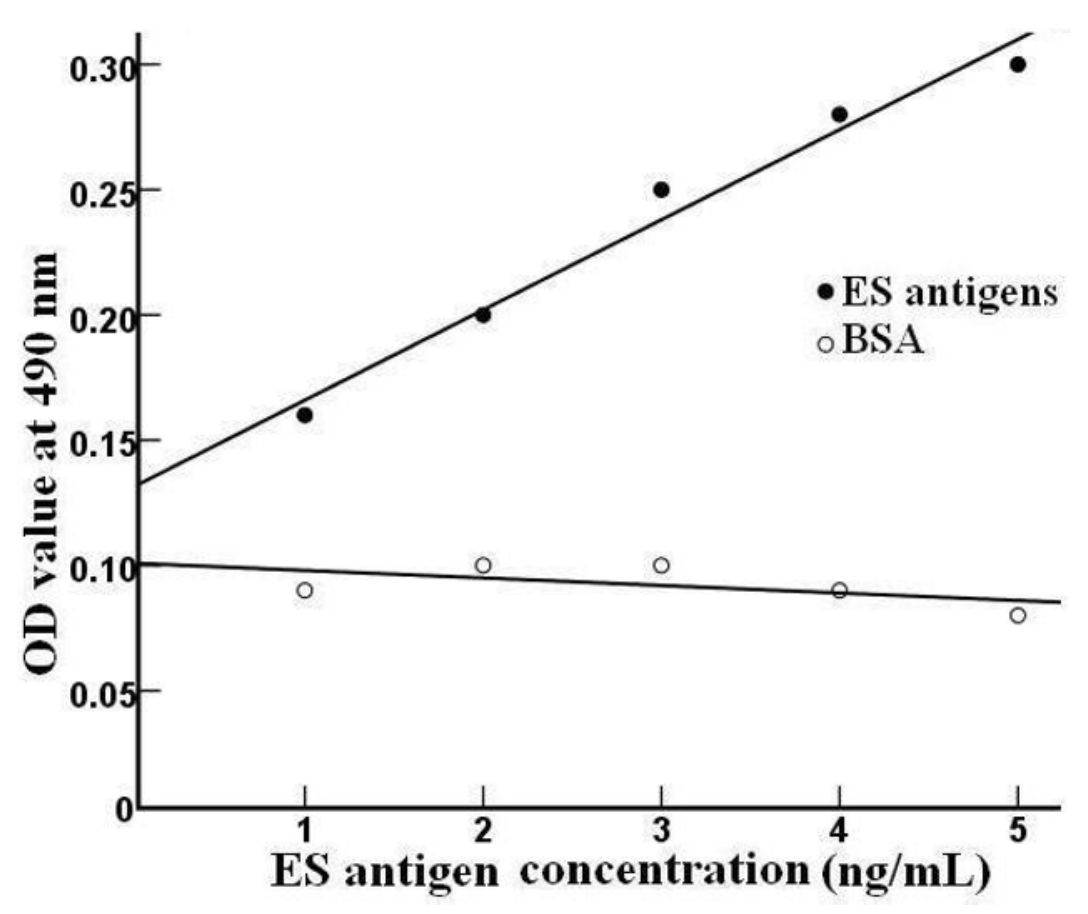

Fig. 2. Relationship between ES antigen concentration and OD value. BSA was used as negative control. Antigen levels are expressed as mean OD values measured with IgY-sandwich ELISA 


\section{Statistical analysis}

All statistical analyses of data were done with SPSS for Windows version 13.0 (SPSS Inc., Chicago, IL). Chi Square Test and Student's $t$-test was used to determine the differences between CAg and antibody at various periods post-infection, difference between the treated group and untreated group, and differences between different time points in the same group with respect to the detection rate and serum level of CAg and antibody. A $P$ Value of $<0.05$ was considered as significant. Wilcoxon rank sum test was used to compare the differences of the number of recovered larvae between treated group and untreated group.

\section{Results}

\section{Analysis of $\operatorname{Ig} Y$}

On average, $70 \mathrm{mg}$ of IgY was extracted from each immunized egg yolk. SDS-PAGE analysis showed two major protein bands with molecular weight of $67 \mathrm{kDa}$ and $29 \mathrm{kDa}$ characteristic of the IgY (Fig. 1).

\section{IgY-sandwich ELISA}

To establish the sensitivity and linearity of IgY-sandwich ELISA, a standard dilution curve of ES antigen concentrations was set up. As clearly illustrated in Figure 2, there was a significant correlation between the OD value and ES antigen concentration, with correlation coefficients being 0.988 . The LDL of ES antigens detected by the assay was
$3 \mathrm{ng} / \mathrm{ml}$ with a linear increase in OD from $1 \mathrm{ng}$ to $5 \mathrm{mg} / \mathrm{ml}$. Furthermore, the results indicated that $\operatorname{IgY}$ was specifically bound to ES antigens.

Kinetics of circulating antigens and antibodies in sera of infected mice

The levels of CAg were determined with all serially collected sera by IgY-sandwich ELISA. Figure 3 shows the CAg levels of different time point. CAg could be detected at $8 \mathrm{dpi}$ with a detection rate of $21.4 \%$. The level of CAg increased dramatically during $13-15 \mathrm{dpi}$ and reached a peak at 22 dpi with $92.8 \%$ of CAg detection rate and remained a plateau for 3 days, then declined gradually. Another peak of CAg occurred at $31 \mathrm{dpi}$ with $58 \%$ of CAg detection rate.

The antibodies against ES antigens was first detected in $14.3 \%$ of the infected mice at $2 \mathrm{wpi}$, and reached a peak at 5 wpi with $100 \%$ of antibody positive rate (Fig. 4). The difference in the detection rate between CAg and antibodies was statistically significant at $2-5$ wpi $\left(\chi^{2}=9.956\right.$, $P<0.05)$

Effect of chemotherapy on the levels of circulating antigens and antibodies

The CAg levels in the untreated and treated groups showed no difference before treatment $(t=0.093, P>0.05)$, but they had a statistical difference during $2-6$ days after treatment $(t=4.243, P<0.05)$ (Fig. 5). Compared with

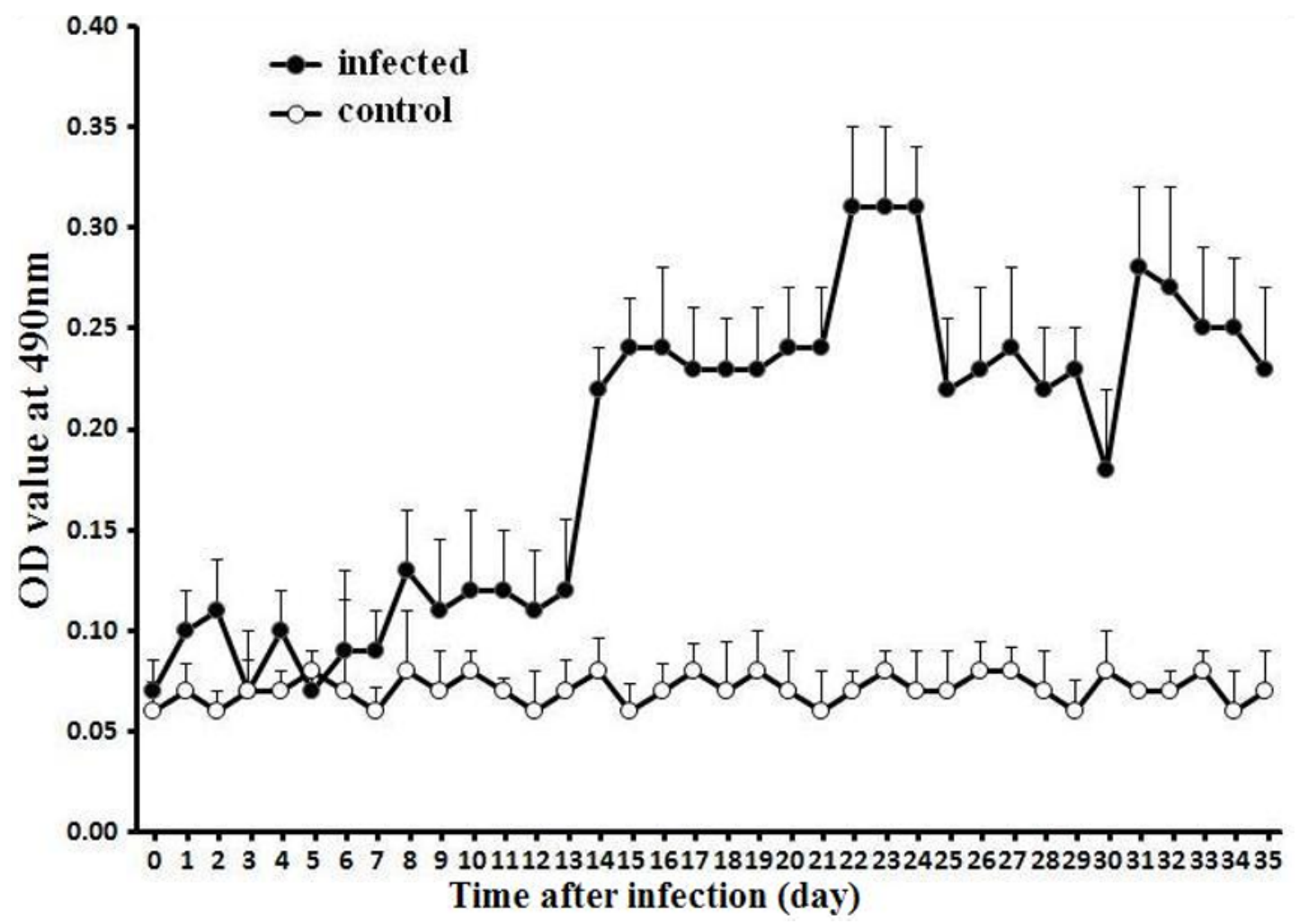

Fig. 3. Kinetics of circulating antigens in sera of mice experimentally infected with $T$. spiralis at different time intervals after infection. Circulating antigens were detected by a sandwich ELISA with $\operatorname{IgY}$ as the capturing antibodies and mouse polyclonal antibody IgG to ES antigens as a detecting antibody. Each mouse was given an oral dose of 500 infective larvae. The sera of no-infected mice were used as negative control. Antigen levels are expressed as the mean $\mathrm{OD}$ value $\pm \mathrm{SD}$ of the individual serum sample 


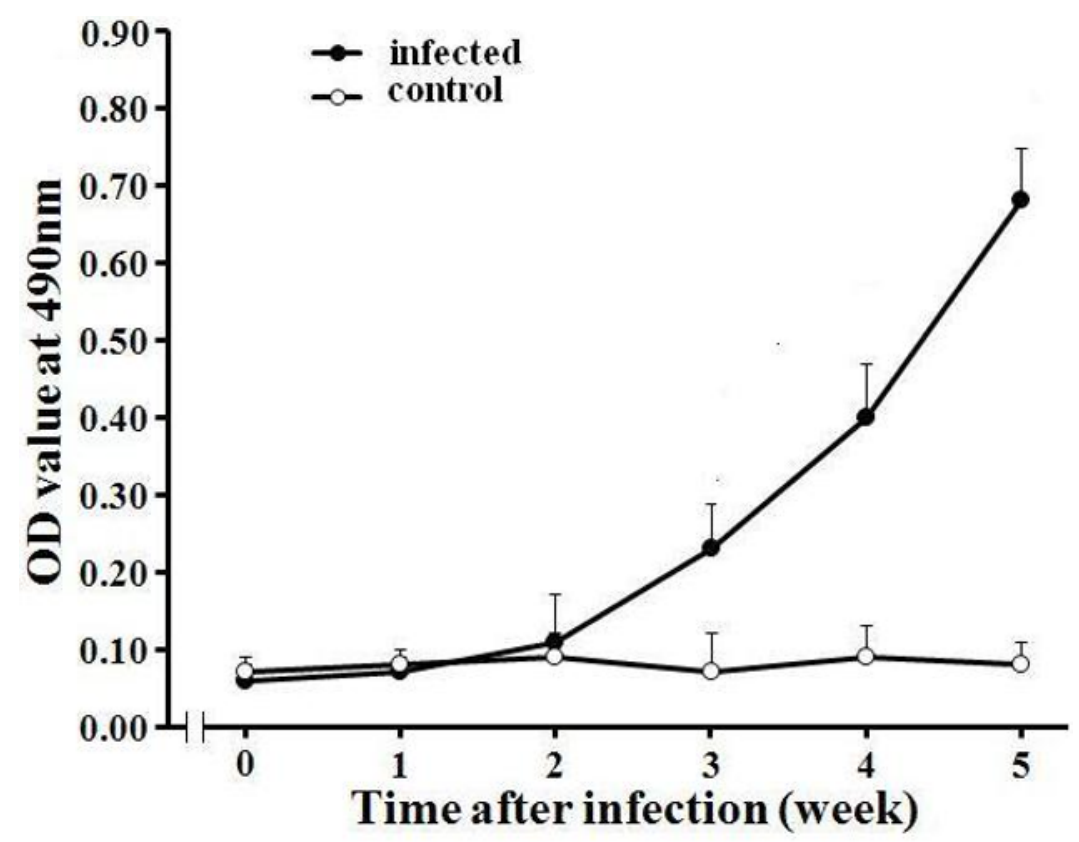

Fig. 4. Kinetics of circulating antibodies in sera of mice experimentally infected with $T$. spiralis at different time intervals after infection. Circulating antibodies were detected by an indirect ELISA with ES antigens of $T$. spiralis muscle larvae. Each mouse was given an oral dose of 500 infective larvae. The sera of no-infected mice were used as negative control. Antibody levels are expressed as the mean OD value \pm SD of the individual serum sample.

that of untreated group, the serum levels of CAg in treated group increased significantly during $2-6$ days posttreatment and then showed rapid decline during $8-14$ days post-treatment. By 42 days after treatment, the CAg levels decreased to the undetected level.

However, as clearly illustrated in Figure 6, the serum levels of antibodies in the treated groups decreased slowly at $1-6 \mathrm{wpt}$, but the antibody levels in the treated and untreated groups showed no difference $(\mathrm{t}=-2.219$, $P>0.05)$. By $6 \mathrm{wpt}$, the detection rate of antibodies was still $100 \%$ in both groups.

At the end of the study (6 wpt), all the infected mice were slaughtered. The number of larvae recovered from the treated group was $382 \pm 96$ larvae, which was significantly

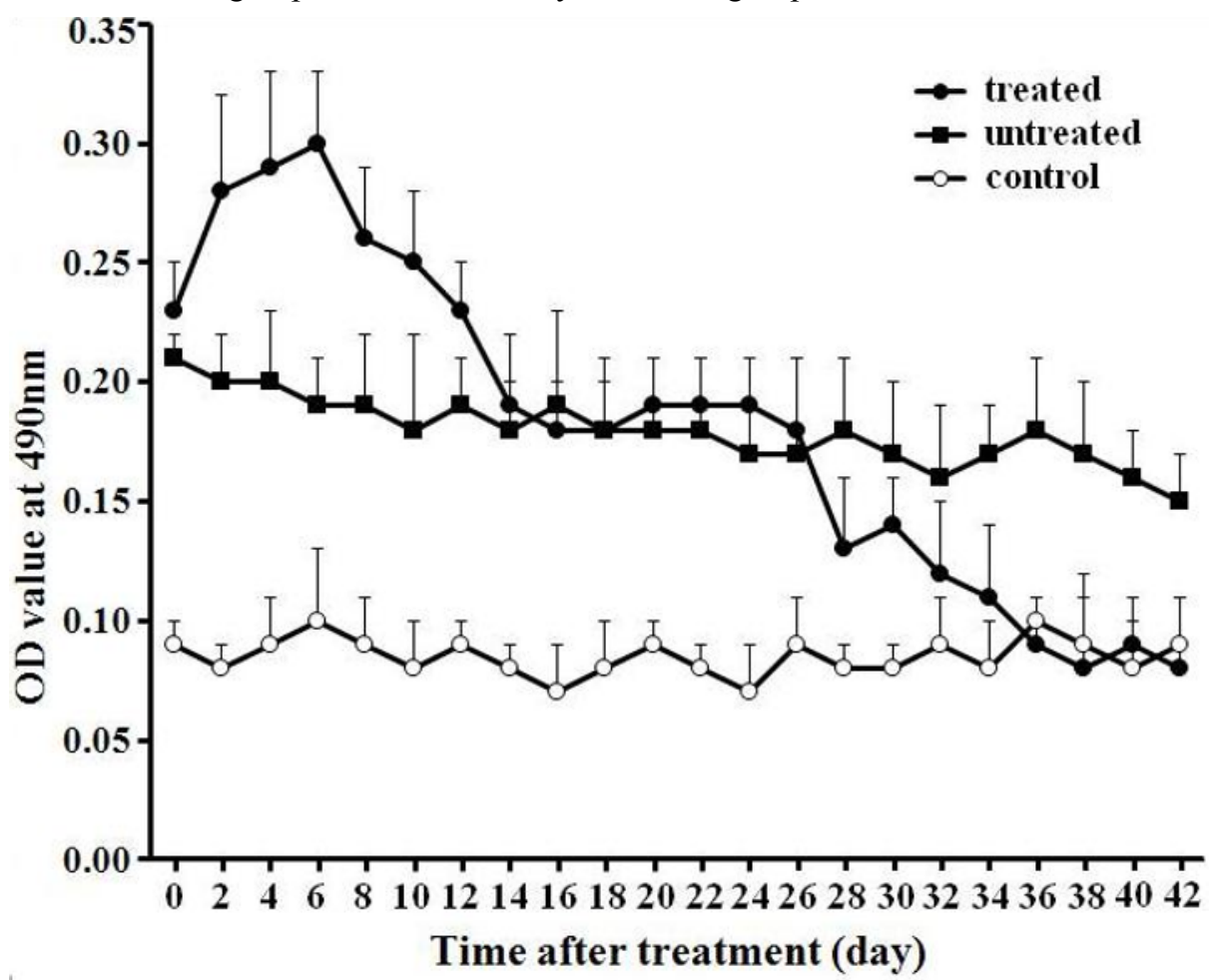

Fig. 5. Comparison of circulating antigen levels in sera of infected mice treated and untreated with albendazole. Albendazole was intragastrically administered at 5 weeks post-infection ( 0 week after treatment). The sera of no-infected mice were used as negative control. Antigen levels are expressed as the mean $\mathrm{OD}$ values $\pm \mathrm{SD}$ of the individual serum sample. 


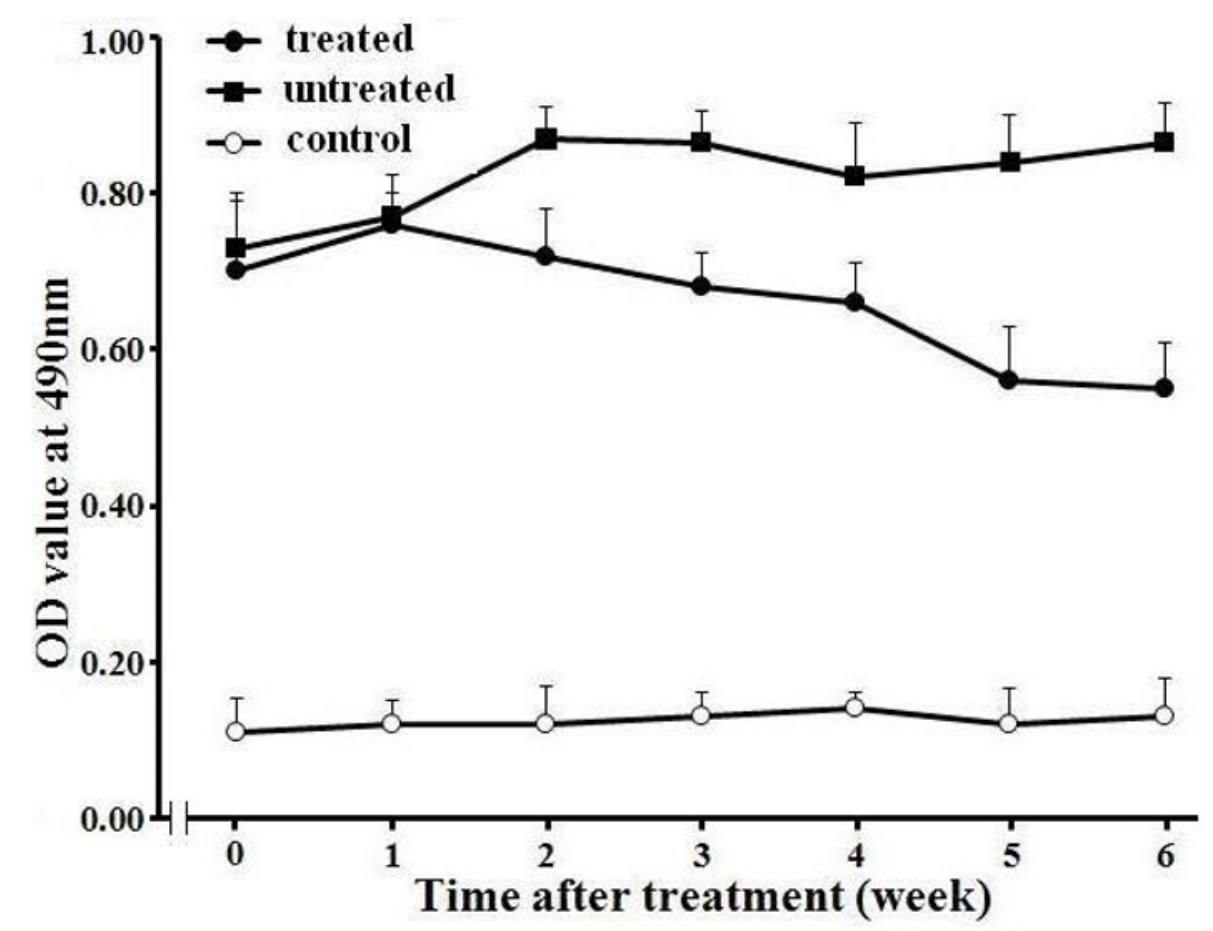

Fig. 6. Comparison of circulating antibody levels in serum samples of infected mice treated and untreated with albendazole. Albendazole was intragastrically administered at 5 weeks post-infection ( 0 week after treatment). The sera of no-infected mice were used as negative control. Antibody levels are expressed as the mean $\mathrm{OD}$ value $\pm \mathrm{SD}$ of the individual serum.

lower than $103720 \pm 8699$ larvae recovered from untreated group $(Z=-3.139, P<0.01)$, and the larval reduction rate in the treated group was $99.6 \%$.

\section{Discussion}

The CAg that is excreted into the host body of macromolecular particles by live worm, mainly worms shedding secretion and excretion, can distribute throughout in various tissues. Hence, the positive CAg implies persistence of living parasites, the amount of CAg was closely parallel to the worm burden in the host. Compared with detection of circulating antibodies, antigen detection might be a useful confirmatory test of parasite infection because it is direct demonstration of parasite products in the circulation (Smith et al., 1984; Ivanoska et al., 1989). The level of CAg in serum fluctuates widely at various periods post-infection. Therefore, for serodiagnosis, it is necessary to use an extremely sensitive and stable method which can detect slight quantities of CAg. Otherwise, the false-negative results may easily be obtained. This may account for detection $\mathrm{CAg}$ in only $13 \%, 29.9 \%$ and $>30 \%$ of the clinical cases with trichinellosis by immunoradiometric assay, sandwich ELISA and dot-blot (Ivanoska et al., 1989; Nishiyama et al., 1992; Dzbenski et al., 1994).

In this work, immunization of Roman hens with ES antigens of $T$. spiralis muscle larvae presented specific IgY in the egg yolks. The average amount of $70 \mathrm{mg}$ of $\mathrm{IgY}$ against ES antigens was harvested for each egg, which indicated that IgY was transited to egg yolk at high levels.
The analysis of the recovered IgY by SDS-PAGE showed a good purity. It indicates that Roman hens, as the host for the production of IgY to ES antigens, show the remarkable ability to rapidly and efficiently generate an abundant IgY and provide specific IgY in a noninvasive way.

Monoclonal antibodies (mAbs) have been used in sandwich ELISA, since the reactivity pattern of each mAb is addressed to a specific molecule epitope (Youssef et al., 1989). The LDL of CAg was $35 \mathrm{ng}$ antigen/ml (Arriaga et al., 1995). Although we used polyclonal IgY and IgG instead of a mAb, the sensitivity of IgY-sandwich ELISA could reach $3 \mathrm{ng}$ antigens $/ \mathrm{ml}$. The assay can be used to evaluate the existence and level of ES antigens in the serum of infected mice because the OD values increase linearly with ES antigen concentrations. Apparently, the application of IgY to ES antigens is advantageous for the detection of circulating antigens in experimentally infected mice. The factors contributing to the advantage include that chicken $\mathrm{IgY}$ reacts with more epitopes on mammalian antigens and then produce an amplification of the signal due to evolutionary difference (Carlander et al., 1999; Larsson \& Sjouist, 1990).

T. spiralis CAg of the experimentally infected mice was continuously detected by IgY-sandwich ELISA with an early and a late peak of CAg during $8-35$ dpi. The serum $\mathrm{CAg}$ of the infected mice could be detected by a mAbsandwich at 11 dpi (Youssef et al., 1989). Similar observations regarding the two peaks of CAg have also been found in experimental infected mice and pigs (Arriaga et al., 1995; Li \& Ko, 2001). In this study, the level of CAg increased dramatically during $13-15$ dpi, 
which was probably related to the massive migration of the newborn larvae released by gravid females to the skeletal muscles. The two peaks of CAg occurred at 22 dpi and 31 dpi when the larvae have developed to the infective stage and the encapsulated of the parasite had been completed. The increase of CAg levels, as detected in this study, seems to correlate with the establishment of muscle larvae in infected animals (Murrell, 1985). The subsequent decline in CAg level may be due to the formation of immune complexes which in turn are eliminated by the host (Arriaga et al., 1995).

Compared with detection of the circulating antigen, circulating antibodies were detected in $12.3 \%$ of the infected mice at 2 wpi, the antibody detection rate was only $35.7 \%$ at 3 wpi, and it reaches $100 \%$ at 5 wpi. Although the sensitivity of the antibody detection was higher than antigen detection at 5 wpi, it appears relatively late and cannot discriminate between the past and present infection. CAg is present in the serum only during active infection, and the levels of CAg continue to decrease after successful chemotherapy. Thus, detection of CAg can also be used as an effective way to evaluate the efficacy of chemotherapy. Our result shows that the serum levels of CAg increased significantly during $2-6$ days posttreatment. The sharp increasing of the CAg might be induced by the larvae destroyed by albendazole. At the end of the experiments, the larval reduction rate in the treated group was $99.6 \%$, which indicated that the chemotherapy was efficient. Our results show that the CAg drops down to the undetected level by 6 weeks after treatment with albendazole, which indicates that the novel assay can be used to evaluate the efficacy of chemotherapy. Similar observations regarding the killing effects of albendazole on the encapsulated $T$. spiralis larvae in muscles have been reported. A reduction of $75.5 \%$ in the parasitic load was observed, when the mice infected with $10 \mathrm{~T}$. spiralis muscle larvae were treated by using under-dosed with albendazole (20 mg/kg for 7 days) at $40 \mathrm{dpi}$ (de-la-Rosa et al., 2007). While albendazole (200 mg/kg for 7 days) was given to the mice infected with 100 larvae at $35 \mathrm{dpi}$, the larval reduction rate was $71.8 \%$ at 15 days after treatment (Xue et al., 2010). The efficacy of albendazole against the larvae in muscle tissues depend on the time between infection and treatment and could be dose-dependent. The later the treatment is prescribed, the higher the probability that the infected will harbor viable larvae in their muscles (Dupouy-Camet et al., 2002).

In conclusion, the IgY- sandwich ELISA appears to be a sensitive and feasible assay for detection of antigenemia of $T$. spiralis and valuable to assess the efficacy of chemotherapy in murine trichinellosis. However, the method for detection of circulating $T$. spiralis antigens did not allow the identification of the infected mice during the first week after infection, although it was able to detect as little as 3 ng antigens $/ \mathrm{ml}$. The IgY and monoclonal antibodies against the early antigens of $T$. spiralis larvae needs to be studied and applied to the antigen detection.

\section{Acknowledgements}

This work was supported by the National Natural Science Foundation of China (No. 81172612 and 81271860) and the Project of Henan Medical Science and Technology (No. 201202016).

\section{References}

AKITA, E. M., NAKAI, S. (1993): Comparison of four purification methods for the production of immunoglobulins from eggs laid by hens immunized with an enterotoxigenic E.coli strain. J. Immunol. Methods, 160: 207 - 214. DOI: 10.1016/0022-1759(93)90179-B

Arriaga, C., Yepez-Mulia, L., Morilla, A., OrtegaPIERRES, G. (1995): Detection of circulating Trichinella spiralis muscle larva antigens in serum samples of experimentally and naturally infected swine. Vet. Parasitol., 58: 319 - 326. DOI: 10.1016/0304-4017(94)00775-8

BRADFORD, M. M. (1976): A rapid and sensitive method for the quantitation of microgram quantities of protein utilizing the principle of protein-dye binding. Anal. Biochem., 72: 248 - 254. DOI: 10.1016/0003-2697(76) 90527-3

Bruschi, F., TAssi, C., Pozio, E. (1990): Parasite specific antibody response in Trichinella sp. human infection: A one year follow-up. Am. J. Trop. Med. Hyg., 43: $186-193$

Carlander, D., Kollberg, H., Wejaker, P. E., LarSSON, A. (2000): Peroral immunotherapy with yolk antibodies for the prevention and treatment of enteric infections. Immunol. Res., 21: 1 - 6. DOI: 10.1385/IR:21:1:1 ChOY, W. F., LIM, P. L., NG, M. H. (1988): A comparison of immunological methods for the detection of Trichinella spiralis antigen. J. Immunol. Methods, 113: 17 - 24. DOI: 10.1016/0022-1759(88)90377-8

CuI, J., JiAng, P., LIU, L. N., WANG, Z. Q. (2013): Survey of Trichinella infection in domestic pigs of northern and eastern Henan, China. Vet. Parasitol., 194: 133 - 135. DOI: 10.1016/j.vetpar.2013.01.038

CUI, J., WANG, Z. Q., XU, B. L. (2011): The epidemiology of human trichinellosis in China during 2004 - 2009. Acta Trop., 2011,118: 1 - 5. DOI: 10.1016/j.actatropica.2011.02. 005

De-La-Rosa, J. L., Alvarez, N., Gomez-Priego, A. (2007): Study of the reproductive capacity of Trichinella spiralis recovered from experimentally infected mice under-dosed with albendazole or mebendazole. Trop. Biomed., 24: 93 - 97

De-La-Rosa, J. L., Moran-Tlatelpa, E., Medina, Y., Gomez-Priego, A., CORREA, D. (2001): Detection of circulating and fecal Trichinella spiralis antigens during experimental infection using monoclonal antibodies against the new born larvae. Parasite, 8: S123 - S125

Dias Da Silva, W., Tambourgi, D. V. (2010): IgY: A promising antibody for use in immunodiagnostic and in immunotherapy.Vet. Immunol. Immunopathol., 135: 173 180. DOI: $10.1016 /$ j.vetimm.2009.12.011 
Dupouy-CAmet, J., KociecKa, W., Bruschi, F., BolasFernandez, F., POZIO, E. (2002): Opinion on the diagnosis and treatment of human trichinellosis. Expert Opin. Pharmacother., 3: 1117 - 1130. DOI: 10.1517/1465 6566.3.8.1117

DVOROŽŇÁKOVÁ, E., HuRNíKOVÁ, Z., KoŁODZIEJSOBOCIŃSKA, M. (2010): Kinetics of specific humoral immune response of mice infected with low doses of Trichinella spiralis, T. britovi, and T. pseudospiralis larvae. Helminthologia, 47: 152 - 157. DOI: 10.2478/s116 87-010-0023-x

DVOROŽŇÁKOVÁ, E., JALČOVÁ, M., HuRNíKOVÁ, Z. (2013): Differences in cellular immune responses of mice $\mathrm{BALB} / \mathrm{c}$ to low and high infective doses of Trichinella spiralis. Helminthologia, 4: 244 - 253. DOI: 10.2478/s116 87-013-0137-z

DVOROŽŇÁKOVÁ, E., KoŁODZIEJ-SOBOCIŃSKA, M., HuRNÍKOVÁ, Z. (2012): Trichinella spiralis reinfection: changes in cellular and humoral immune response in BALB/c mice. Helminthologia, 49: 201 - 210. DOI: 10.2478/s11687-012-0039-5

Gamble, H. R., Pozio, E., Bruschi, F., Nockler, K., KAPEL, C. M., GAJADHAR, A. A. (2004): International Commission on Trichinellosis: recommendations on the use of serological tests for the detection of Trichinella infection in animals and man. Parasite, 11:3-13

Gomez-Morales, M.A., Ludovisi, A., AMATI, M., Cherchi, S., Pezzotti, P., PozIO, E. (2008): Validation of an enzyme-linked immunosorbent assay for diagnosis of human trichinellosis. Clin. Vaccine Immunol., 15: 1723 1729. DOI: $10.1128 /$ CVI.00257-08

Hegazy, I. H., El Mansoury, S. T., Boulos, L. M. (1996): Detection of circulating Trichinella pseudospiralis antigen by enzyme linked immunosorbant assay (ELISA). J. Egypt Soc. Parasitol. 26: 217 - 225

IVANOSKA, D., Cuperlovic, K., Gamble, H. R., Murrell, K. D. (1989): Comparative efficacy of antigen and antibody detection tests for human trichinellosis. $J$. Parasitol., 75: 38 - 41. DOI: 10.2307/3282932

JuliarenA, M., Gutierrz, S., CERIANI, C. (2007): Chicken antibodies: a useful tool for antigen capture ELISA to detect bovine leukaemia virus without crossreaction with other mammalian antibodies. Vet. Res. Commun., 31: 43 - 51. DOI: 10.1007/s11259-006-3422-1

KAPEL, C. M., GAMBle, H. R. (2000): Infectivity, persistence, and antibody response to domestic and sylvatic Trichinella spp. in experimentally infected pigs. Int. J. Parasitol., 30: 215 - 221. DOI: 10.1016/S00207519(99)00202-7

KOŁODZIEJ-SOBOCIŃSKA, M., MACHNICKA-ROwIŃSKA, B. (2012): In vivo inhibition of inducible nitric oxide synthase by aminoguanidine influences free radicals production and macrophage activity in Trichinella spiralis infected low responders (C57BL/6) and high responders (BALB/c) mice. Helminthologia, 49: 189 - 200. DOI: 10.2478/ s11687-012-0038-6

LARSSON, A., SJOUIST, J. (1988): Chicken antibodies: a tool to avoid false positive results by rheumatoid factor in latex fixation tests. J. Immunol. Methods, 108: 205 - 208. DOI: 10.1016/0022-1759(88)90420-6

LARSSON, A., SJOUIST, J. (1990): Chicken IgY: utilizing the evolutionary difference. Comp. Immunol. Microbiol. Infect. Dis., 13: 199 - 201. DOI: 10.1016/0147-9571(90) 90088-B

LARSSON, A., WeJAKER, P. E., ForsBerG, P. O., LindAhL, T. (1992): Chicken antibodies: a tool to avoid interference by complement activation in ELISA. J. Immunol. Methods, 156: 79 - 83. DOI: 10.1016/0022-1759(92)90013-J

LI, C. K., Ko, R. C. (2001): The detection and occurrence of circulating antigens of Trichinella spiralis during worm development. Parasitol. Res., 87: 155 - 162

Li, F., Cui, J., Wang, Z. Q., JiAnG, P. (2010): Factors affecting the sensitivity of artificial digestion and its optimization for inspection of Trichinella spiralis in meat. Foodborne Pathog. Dis., 7: 879 - 885

Li, X. X., Cui, J., Jing, F. J., WANG, Z. Q. (2010): Production and identification of IgY against excretorysecretory antigens of Trichinella spiralis muscle larvae. Chin. J. Zoonoses, 26: 1028 - 1031 (In Chinese)

Morakote, N., Khamboonruang, C., Siriprasert, V., SuphaWITAYANUKUL, S., MarCANANTACHOTI, S., THAMASONTHI, W. (1991): The value of enzyme-linked immunosorbent assay (ELISA) for diagnosis of human trichinosis. Trop. Med. Parasitol., 42: 172 - 174

Murrell, K. D. (1985): Trichinella spiralis: Acquired immunity in swine. Exp. Parasitol., 59: 347 - 354

Nishiyama, T., Araki, T., MizunO, N., WadA, T., IDE, T., YAMAGUCHI, T. (1992): Detection of circulating antigens in human trichinellosis. Trans. R. Soc. Trop. Med. Hyg., 86: 292 - 293. DOI: 10.1016/0035-9203(92)90316-5

Oltean, M., Gavrea, R., Dumitrache, M., BĂGuț, T., Gherman, C. M., Cozma, V., Györke, A. (2012): Characterization of host-parasite interactions during the experimental Trichinella spiralis infection in pigs. Helminthologia, 50: 139 - 146. DOI: 10.2478/s11687-012-0029-7 PozIO, E. (2007): World distribution of Trichinella spp. infections in animals and humans. Vet. Parasitol., 149: 3 21. DOI: 10.1016/j.vetpar.2007.07.002

Pozio, E., Gomez-Morales, M. A., Dupoupy-Camet, J. (2003): Clinical aspects, diagnosis and treatment of trichinellosis. Expert Rev. Anti-Infect. Ther., 1: 471 - 482. DOI: 10.1586/14787210.1.3.471

Rodriguez-Osorio, M., Abad, J. M., De Haro, T., VILlA-REAL, R., GOMEZ-GARCIA, V. (1999): Human trichinellosis in Sourthern Spain: serologic and epidemiologic study. Am. J. Trop. Med. Hyg., 61: $834-837$

SMith, H.V., KenNedy, M. W. (1984): Soluble antigens and antibodies in the sera of mice infected with Trichinella spiralis, detected by a modified double counterimmunoelectrophoresis technique. J. Helminthol., 58: $71-78$ Sunwoo, H. H., WANG, W.W., Sim, J. S. (2006): Detection of Escherichia coli O157:H7 using chicken immunoglobulin Y. Immunol. Lett. 106: 191 - 193. DOI: 10.1016/j.imlet.2006.05.005

SvendSEN, B., HAU, J. (1996): Chicken eggs in polyclonal antibody production. Scand. J. Lab. Ann. Sci., 23: 85-91 
Tini, M., Jewell, U. R., Camenisch, G., Chilov, D., GASSMANN, M. (2002): Generation and application of chicken egg-yolk antibodies. Comp. Biochem. Physiol. A: Mol. Integr. Physiol., 131: 569 - 574. DOI: 10.1016/ S1095-6433(01)00508-6

Wang, S. W., WAnG, Z. Q., CuI, J. (2011): Protein change of intestinal epithelial cells induced in vitro by Trichinella spiralis infective larvae. Parasitol. Res., 108: 593 - 599. DOI: $10.1007 / \mathrm{s} 00436-010-2102-9$

LIU, L. N., Jing, F. J., CUI, J., Fu, G. Y., WAnG, Z. Q. (2013): Detection of circulating antigen in serum of mice infected with Trichinella spiralis by an IgY-IgM mAb sandwich ELISA. Exp. Parasitol., 133: 150 - 155. DOI: 10.1016/j.exppara.2012.11.001

WANG, Z. Q., CUI, J., WeI, H. Y., HAN, H. M., ZHANG, H. W., LI, Y. L. (2006): Vaccination of mice with DNA vaccine induces the immune response and partial protection against T. spiralis infection. Vaccine, 24: 1205 - 1212. DOI: 10.1016/j.vaccine.2005.08.104

WANG, Z. Q., CuI, J., Wu, F., MAO, F. R., JiN, X. X. (1998): Epidemiological, clinical and serological studies on trichi- nellosis in Henan Province, China. Acta Trop., 71: 255 268. DOI: 10.1016/S0001-706X(98)00072-2

WANG, Z. Q., FU, G. Y., JING F. J., JIN, J., REN, H. J., JIANG, P., CUI, J. (2012): Detection of Trichinella spiralis circulating antigens in serum of experimentally infected mice by an IgY-mAb sandwich ELISA. Foodborne Pathog. Dis.,9: 727 - 933. DOI: 10.1089/fpd.2012. 1157

Xue, J., XiaO, S. H., Xu, L. L., Zhang, Y. N., QianG, H. Q. (2010): Efficacy of tribendimidine and albendazole in treating mice infected with Trichinella spiralis. Chin. J. Parasitol. Parasit. Dis., 28: 8 - 11 (In Chinese)

Year, H., Andiva, S., Perret, C., Limonne, D., Boireau, P., DupouY-CAMET, J. (2003): Development and evaluation of a Western blot kit for diagnosis of human trichinellosis. Clin. Diagn. Lab. Immunol., 10: 793 - 796. DOI: $10.1128 /$ CDLI.10.5.793-796.2003

Youssef, M. Y., Barakat, R., Boulos, L. M., El-MaNSOURY, S. T. (1989): Preparation and use of monoclonal antibodies in the detection of Trichinella spiralis circulating antigen. J. Egypt Public Health Assoc., 64: 105 - 122 